\title{
Effects of Self Managing Life Crisis Based on the Oriental towards
}

\section{Life Crisis and Well-being of Married Women}

\author{
Ungsinun Intarakamhang (Corresponding author) \\ Behavioral Science Research Institute (BSRI), Srinakharinwirot University \\ 114 Sukhumvit 23 Rd. Bangkok 10110, Thailand \\ E-mail: ungsinun@swu.ac.th \\ Tasana Thongpukdee \\ Behavioral Science Research Institute (BSRI), Srinakharinwirot University \\ 114 Sukhumvit 23 Rd., Bangkok 10110, Thailand \\ E-mail: tasana@swu.ac.th
}

\begin{abstract}
The main objectives were: 1) to study the efficiency of Managing Life Crisis Program (MLCP) based on the oriental approach towards the self-perception of life crisis, 2) to investigate an interaction between psycho-social characteristics (of neuroticism, self control and social support) and MLCP, and 3) to study the variables predicting the well-being. Subjects, who scored high on self perception of life crisis, were mothers of sixth graders. Using simple random sampling, 32 participants were selected as the experimental group and 40 as the control group. Data was analyzed by MANOVA statistics and multiple regression. The results indicated that after training the experimental group who trained with MLCP, scored lower on the total perception of life crisis, emotion oriented coping, and adapting. These scores were statistically significant different at 0.05 level from the control group. No interaction was observed among psycho-social characteristics and training program towards the self- perception of life crisis. Finally adapting, emotion oriented coping, and stress predicted the well-being of participants at $41.1 \%$.
\end{abstract}

Keywords: Managing life crisis, Midlife crisis, Well-being, Married women

\section{Introduction}

The foundation of this research is based on the weakening of inter family relationships. As family is considered the primary social unit of human beings. According to the National Economic and Social Development board Plan, efforts should focus on building happiness of the people. Hence more organizations are trying to promote the concept of self-sufficiency and to uphold the philosophy of Sufficiency Economy of H.M. King Bhumibol Adulyadej, the King of Thailand (Wattanasiritham, 2006). Should all family members realize that happiness is the foundation of development, they would develop a positive attitude towards having a healthy body, and hence be able to lead their families, society and eventually the country towards the sustainable social and economic growth.

The statistic of self-injury or suicide from the Department of Mental Health in 2005 showed that the suicide rate was approximately 16-20 cases/day or 1 case/ $1 \frac{1}{2}$ hours. The most successful suicide rate was $24.9 \%$ for persons between 30-39 years. The females had a suicide rate that was three times higher than males. The factors predisposing suicide were mostly a quarrel with close person $(36 \%)$; petulance at being condemned or being blamed (33\%); about love (21\%), and about sorrow (13\%). The diseases found as the precipitating factor for successful suicide were chronic diseases (57.3\%); depression (22.4\%); psychosis (10.9\%) and increasing stress. The statistic from the Department of Mental Health also showed that the patients visiting stress relaxation clinic, had increased from 5,209 cases in 2004 to 5,746 cases in 2005.

The individual who fails to manage the midlife crisis may experience mental disequilibrium or emotional crisis as it is called and if the problem is still hidden, it may become more depressing and lead to false beliefs until that person may falsely decide to end up his/her life or to lose property, or tend to abuse, vent anger upon children, and family, till it finally regresses the working potentiality. 
Women play several roles in the Thai society. They continue to be principally responsible for childcare and housework. In addition, women working outside the homes tend to have the same responsibilities as men in their work contexts. Moreover, the degenerative changes in the body, and declined sex hormone can cause both internal and external stress. This group is therefore at risk to become stressed, which is considered as a life crisis. But if those women perceive that such a risk as life challenging, then it will promote individual strength and also life protection. Results of Intarakamhang et.al (2008) showed that the factors related to the midlife crisis of employed, Thai married women were neuroticism and experience in life loss, responsibility in family, marital relationship, family support, commitment to Buddhism within family, workload, job promotion, job ambiguity, colleagues and boss support, resident environment and neighbor relationship. The findings also showed that high neuroticism was an important factor that had an impact on life crisis and that correlated with other variables, resulting in the women to perceive more life crisis.

The researchers were therefore interested in training the women in order to build up self protection to cope with the problems. The life crisis management according to the doctrine of Buddhism means adapting through the principles of meditation and body exercise of Taoism. The researchers therefore applied the joint practices of Buddhism and Taoism and studied the interaction of neuroticism, self control and social support on self-perception of life crisis. After training, the midlife women would be able to apply this knowledge and skill to their daily life, to reduce perception of life crisis and enhance their own well-being, and become good quality assets of Thai society.

\section{Objectives of the research}

To study the efficiency of Managing Life Crisis Programme (MLCP), to investigate an interaction between psycho-social characteristics and MLCP that affect the self- perception of life crisis among Thai married women and study the variables predicting the well-being among Thai married women.

\section{Scope of the research}

The research was an application of knowledge from the behavioral sciences about the cognitive theory of Bandura (1989), which stated that change in human behavior was caused by psychological and social factors. The theoretical framework guiding this research and depicting the interaction of the independent and dependent variables is shown in the figure 1.

\section{Research Methodology}

This research was based on the factorial experimental design and correlation was used as the main technique for data analysis.

\subsection{Sample}

The sample group consisted of midlife Thai married women between 35-55 years, who were the mothers of the sixth graders from schools in Bangkok Metropolis. The researchers surveyed perception of life crisis among the mothers of 334 students from six schools. The mothers who were selected were those who scored more than 80 in the perception of life crisis scale, where average score (40-160) was interpreted as moderate perception. A total of 134 persons volunteered participation in this program. Out of these 72 persons participated in all activities full time in the research, with 32 persons as experimental group, who were introduced MCLP based on the oriental approach, and 40 persons as the control group. The control group was given suggestions about self massage and documents about life crisis management of married Thai women, which had been prepared by the researchers.

\subsection{The Procedure}

4.2.1 The MLCP was developed based on the oriental approach of Taoism Doctrine. The proposed programme was sent to three professionals for revision and correction in order to consider its suitability to the objectives of the research and towards making any improvement in the method.

4.2.2 Participants were trained according to the approved MLCP program based on Randomized Control Group Pretest Posttest Design which is shown in Tables 1.

4.2.3 The participants of the research engaged in three activities on a daily basis as they participated in the research between March-April 2009. These activities were:-

i. The first activity was two days of camping to train for the techniques of mental and body management through workshops about Taoism doctrine, meditation, nine postures of Tai-chi, body exercise with Chinese music and stress relief through physical exercise with dance music. 
ii. The second activity was a group activity and self analysis to find out the causes and solutions to cope with crisis and make changes in the body and mental management.

iii. The third activity was self massage training for relaxation according to Thai traditional principle and the adjustment of body and mental management according to Buddhism. For the control group was suggested to train relaxation by self massage and given documents about coping and preventing life crisis for midlife Thai married women. These documents were prepared by the researchers for self-study by the participants.

4.2.4 Data was collected from the sample group in three phases. The first time was to collect pretest data by measuring all variables; the second time was to collect posttest data immediately after training to measure perception of life crisis variable and the third time was to measure after three months of the second test to measure the well-being variables.

4.2.5 The performance of the sample group was monitored up by self reports of the participants at home, and also by taking interview from them to collect qualitative data about training program and result of training as data to support the research evidence.

\subsection{Research instruments}

Trial use of the instruments was conducted with the mothers of the sixth graders, who were studying in three schools in Bangkok Metropolis. A total of 289 persons were surveyed. Cronbach coefficient analysis of the questionnaires is depicted in Table 2.

\subsection{Data Analysis}

The data obtained from the research was analyzed using SPSS analysis program. General data and the variables for descriptive analysis were presented in percentile, mean, and standard deviation. F-Test by MANOVA statistic and multiple regression analysis were conducted to test the hypothesis.

\section{Results}

The research findings have been tabulated and the analyses of these findings were concluded according to the stated hypotheses as follows:-

5.1 After training, it showed that midlife Thai married women who had been trained using the MLCP based on the oriental approach in experimental group, had overall score of self perception of life crisis lower than untrained Thai women in control group. Thus, the hypothesis 1 was supported and is shown in table 3. After analysis of variance of each variable for the crisis perception, it was found that after the test, stress scores of the experimental and control groups were not different but emotion oriented coping and adaptation of the experimental and control group showed statistically significant difference at 0.05 levels as shown in table 4 .

5.2 For the experimental group after training, it showed that midlife Thai married women who had been trained with MLCP based on the oriental approach had overall scores of perception of life crisis lower than before training. Thus, the hypothesis 2 was supported as shown in table 5. Considering the variance of each variable for perception of life crisis, it showed that the scores on stress of both pretest and posttest of the experimental group were not different, but the scores of emotion oriented coping and adaptation were lower than before training at statistical significance at 0.05 as shown in table 6 .

5.3 The results showed that for the experimental group, of the midlife Thai married women who had been trained with MLCP based on oriental approach, and had received social support had statistically significant different scores (at .05 levels) on perception of life crisis when compared to the control group. Thus, the hypothesis was supported.

5.4 For the experimental group, the midlife Thai married women who had been trained on MLCP based on oriental approach, and who had different scores of neuroticism also had different overall perception of life crisis, statistically significant at 0.05 . Thus, the hypothesis was supported.

5.5 The overall self crisis perception of the midlife Thai married women with varying levels of self control and who had been trained with MLCP was not different. This did not support hypothesis. Upon consideration only the variance of each of 3 perception of life crisis, it showed that the group having different self control level, the score of perception of life crisis in terms of stress, emotion oriented coping and inappropriate adaptation were not different.

5.6 The midlife Thai married women who had low scores on neuroticism but high scores on social support, upon being trained by MLCP based on oriental approach (stress mean $=42.11, \mathrm{SD}=11.24$, problem coping mean $=$ 
13.00, $\mathrm{SD}=3.00$ and adaptation mean $=19.11, \mathrm{SD}=3.37$ ) had lower scores in overall life crisis for each variable, i.e. stress, emotion oriented coping and adaptation, lower than the women who scored high on neuroticism, and lower on social support and also from the group not trained (Stress mean $=25.92, \mathrm{SD}=7.34$; emotion oriented coping mean $=18.92, \mathrm{SD}=5.66$ and adaptation mean $=27.67, \mathrm{SD}=7.27$ ). These differences were not statistically significant. Thus, these findings did not support hypothesis.

5.7 The midlife Thai married women who scored high on self control and social support, after been trained by MLCP based on oriental approach (stress mean $=32.25, \mathrm{SD}=14.64$; problem coping mean $=14.00, \mathrm{SD}=2.98$ and adaptation mean $=21.00, \mathrm{SD}=4.00)$ scored lower on overall perception of life crisis and each of its variables, i.e. stress, emotion oriented coping and adaptation as compared to the women who had lower self control, lower social support and had not been trained (Stress mean $=34.40, \mathrm{SE}=9.26$; problem coping mean $=18.67, \mathrm{SD}=3.44$ and adaptation mean $=28.00, \mathrm{SD}=4.93$ ). These differences were not statistically significant. Thus, these findings did not support hypothesis.

5.8 Stress, emotion oriented coping and adaptation could predict well-being of midlife Thai married women at a moderate level or $41.1 \%$ and adaptation had greatest influence over well-being in opposite direction $(\beta=0.741)$. Second was emotion oriented coping $(\beta=0.185)$ and last was stress $(\beta=0.021)$. These findings supported the hypothesis.

\section{Discussion of Results}

The posttest trained Thai married women had lower perception of life crisis as compared to the pretest group and women who had not been trained. These findings supported the theoretical viewpoint of Lazarus and Folkman (1984) who pointed out that when stress is experienced by an individual they turn to social support in varying degrees. The individual then tries to solve any perceived problem by applying problem focused coping. However, if it were a serious problem, emotion oriented coping was applied and this would yield better results if they had social support.

These findings also conform to the study of Hasida (2005) who studied the problem focused coping of 510 Israeli persons. This study found that emotion oriented coping using cognitive appraisal was a less effective mechanism to reduce stress as compared to relaxation, which revealed positive results.

In addition, the training program based on Taoism was implemented by group activities such boxing, physical exercise, dancing, meditation, socially beneficial activity and merit group discussion. All of these methods yielded positive impact upon the practice of calming the mind and would lead towards the ability of problem focused coping and adaptation to life crisis. Sucaromana and Choochom (2005) used a twenty four hours program based on Taoism to show that it had efficiently promoted the well-being of the participants better than pretest levels and higher than the untrained control group. Additionally, there were several other researches that supported the Buddhism practice in its resultant impact to calm and relax the mind, promote intellectual abilities and to find better solution to the life crisis as also referred to in the research of Tangcholthip (1987). This researcher studied the impact of meditation training on seventeen upper secondary students for eight weeks. The results showed that the experimental group had better mental health in the posttest than in pretest. Similarly in the study of Luangprawat (2004) who studied about meditation to eliminate stress, participant graduate students were trained to practice the four noble truths and muscle contraction. The study showed that the trained group had better stress management than the untrained group.

Further evidence can be found in the research of Aphaijit (1998) who quoted that the technique of self massage was a kind of training that had similar impacts as meditation. Each massage was rhythmic that helped to meditate and calm down the mind to release stress and hence was an exercise for both mind and body.

From the hypothesis, Thai married women in the experimental group who had different levels of social support, had different degree of perception of life crisis. Results of this study showed that social support had impacted perception of life crisis. These findings support the hypothesis and gain evidence from other researches. In a study Maslach (1986; cited in Matyat, 1998) stated that social support had played an important role in reducing stress and exhaustion of work. Similarly in the study of Northouse (1988; cited in Limsila, 2004) it was found that social support would help a person to cope better with stress. Kusuma Na Ayutthaya and Somnarin (1997) found that family support could alleviate feelings of stress in individuals. In addition, Phulsawat (2001) found that the students who had received different levels of social support would have statistically significant different adaptation, and that higher levels of social support would help a person to adapt better with the situation.

These results showed that neuroticism had an impact on the perception of life crisis. The study of Julkathappa (1991) showed that each person who encountered the same problem experienced different reactions due to their 
personality characteristics. For instance a serious and sensitive person tends to feel more stress. This finding also corresponds with the study of Intarakamhang, Choochom and Sucaromana (2007) which highlighted that a sensitive personality had influence in prediction of the perception of life crisis among midlife Thai married women up to 0.13 and had correlation with other variables such as the family income, family support, religious commitment. From the study of Chaichandee (1998) it was found that mental stability was negatively related to stress. Similarly, the study of Chitprasert (2004) found that among the newly graduated nurses, a stronger personality would experience lower levels of stress than a sensitive or weaker personality.

This indicated that self control did not impact perception of life crisis as predicted by some researchers who suggested that self control would reveal better results in the group who had been trained to adapt to deal with conflict behavior or express only suitable behavior. For instance, this group would refrain from smoking, using of illegal drug, connective health care, or experience negative emotion. Referring to the study of Plainsong (2004) who compared the belief of external power and self control on the health of AIDs infected and the non-infected persons, it showed that the degree of self control degree did not make a difference. Phumsrikaew (2002) who studied the correlation between future orientation, self control and physical exercise demand of commercial bank staff, found that self control of the bank staff was positively related in a moderate level with body exercise $(\mathrm{r}=$ $0.3)$.

Results analyzed for testing hypothesis, did not show any correlation among neuroticism, social support and training program, nor in high self control, high social support and training program. These findings may be due to the sample group being subdivided, the comparative group became less than ten persons, which restricted the variance analysis.

Finally the results for testing hypothesis, found that stress, emotion oriented coping and adaptation could predict well-being of midlife married women. These found support from the study of Trakoolsalit (2002) which stated that well-being or better mental health was a result of the positive assessment of stress to perceive the problem, know how to manage stress, relaxation technique, change of perception, feeling more comfortable to accept the genuine situation, feel happy upon being able to find out and solve the problem. These findings also corroborated the study of Shek (1995) who studied midlife Chinese marriage couple and found that the married couples who were unable to adapt themselves to matrimonial life would develop mental symptoms and experience midlife crisis. In this regard, adaptation, stress from social role, family life quality were the factors that could predict the well-being of a married couple and no life crisis was found in the midlife women who prepared themselves to cope with change in their matrimonial life.

\section{Recommendations}

The findings of this study could be applied to improve the ability of married women to deal with midlife crisis. The midlife Thai married women must face several burdens, for instance, taking care of their family members, i.e. parents, children, husband, and relatives, as well as also carry out their responsibility in work life and also the society. Therefore, they have high perception of midlife crisis. It is recommended that these women should be prepared to cope with these changes by oriental training approaches based on Taoism and Buddhism doctrines. These training programs could provide several practices for enjoying physical movement, exercising with music, self massage according to Thai traditional way, breathing and meditation practice. This would enable them to feel relaxed and they would be able to practice the training techniques at any time and place, which is suitable to the urban life where time is an essence.

Further more, the results of this study showed no correlation between the psychosocial characteristics and the training program. This indicates that managing the midlife crisis based on the oriental approach can be applied by all persons regardless of their psychosocial characteristics of personality, self control or social support.

The MLCP program was well applied during the training period. Therefore, its' impact in long term perspective should be studied further to find the appropriate length of training that is required to decrease or eliminate perception of life crisis and also to promote mental defense from the effects of stress or serious problems in life.

\section{Acknowledgements}

This research was financially supported by the Thailand Research Fund (TRF) in jointly with Office of the Higher Education Commission. We greatly appreciate the valuable advice and guidance of Asst.Prof.Wiladluk Chauwanlee, Ph.D., Faculty Member of Behavior Science Research Institute, Srinakharinwirot University.

\section{References}

Aphaijit, S. (1998). Massaging Arts: Release Pain, Sprains for Person Massage and Massaging Client. Bangkok: Center of Mass Media, Bangkok. 
Balan, P. (2006). Crisis Management. Translated from Thai by Larry Barton. Bangkok: Export Net Co., Ltd.

Bandura, A. (1989). Social cognitive theory. In R. Vasta (Ed.), Annals of Child Development, 6. Six theories of child development (pp. 1-60). Greenwich, CT: JAI Press.

Big Bend. Inc. (2003). Understanding crisis theory. Crisis \& Suicide. [Online] Available: http://www.221bigbend.org/nhotlines/suicide/crisistheory.html. (Febuary12, 2005)

Chaichandee, W. (1998). Variables Related to Stress for Laboratory Teaching of Nursing College attached to Praboromarajchanok Institute of Health Workforce Development, Ministry of Public Health. Thesis of Master of Education (Psychology). Bangkok: Srinakharinwirot University.

Chamchitchuen, S. (2004). Crisis Intervention. [Online] Available: http://www.mahidol.ac.th/mahidol.ra. (September 11,2004)

Chitprasert, K. (2004). Work-Related Problems, Hardiness, Self-Esteem and Stress of Novice at Siriraj Hospital. Thesis of Master of Education. (Developmental Psychology). Bangkok: Srinakharinwirot University.

Department of Mental Health. (1999). Consultation to Cope Against Crisis. Bangkok: Ministry of Public Health.

Diener, E.D. (2000). Subjective Well-being. American Psychologist, 55(1), 34-43.

Eysenck, H.J. (1991). Neuroticism. anxiety, and depression. Psychological Inquiry, 2(1), 75-76.

Hasida, Ben-Zur. (2005). Coping Distress and Life Events in a Community Sample. International Journal of Stress Management, 12(2), 188-196.

Intarakamhang, U. (2008). Research Synthesis Concerning the Stress and Coping of Thai People. Journal of Behavioral Science, 14(1), 70-89.

Intarakamhang, U., Choochom, O., \& Sucaromana, A. (2007). Factor Related to Life Crisis of Midlife Married Thai Woman Working in Government Sector, State Enterprise and Private Sector. Journal of Behavioral Science, 13(1), 15-30.

Intarakamhang, U., Raghavan, C., Choochom, O., \& Sucaromana, A. (2008). Causal Relation Analysis and Indics of Midlife Crisis of Employed, Married Thai Women. Journal of Population and Social Studies, 16(2),73-93.

Julkathappa, S. (1991). Dark Risk! From Stress. Saim Rat Newspaper, November 3, pp. 5.

Kusuma Na Ayutthaya, S., \& Somnarin, O. (1997). Family Support and Behavior to Cope with Stress in AIDS Patient. Bangkok: Mahidol University.

Lazarus. R.S., \& Folkman, S. (1984). Stress appraisal and coping. New York: Springer Publishing Company.

Limpanusorn, P. (2004). Tao Doctrine of Lao Jue. Bangkok: “Tek Ka” Jie Jin Koh Foundation.

Limsila, S. (2004). Factors Related to Stress Coping of Nurse in Operation Room of Ramathibodi Hospital. Thesis of Master of Education. (Health Education). Bangkok: Srinakharinwirot University.

Luangprawat, N. (2004). Result of Crisis Management by mean of Mediation, Four Noble Truths Thinking and Muscle Contraction Practice to Cope with Stress of Students. Thesis of Master of Science (Applied Behavioral Research). Bangkok: Graduate School, Srinakharinwirot University.

Matyat, H. (1998). Individual Factor, Working Factor and Mental Factor Related to Boredom of Professional Nurse Working in East Region Hospital Center. Thesis of Master of Education. (Developmental Psychology). Bangkok: Srinakharinwirot University.

Oles, P.K. (1999). Towards a Psychological Model of Midlife Crisis. Psychol Rep, 3(2), 1059-1069.

Phulsawat, D. (2001). Adaptation and Mental Health of Student under the Education Management Program (Phranakhon Rajabhat Institute). Thesis of Master of Education. (Health Education). Bangkok: Srinakharinwirot University.

Pliansong, P. (2004). Comparison the Belief in Internal and External Power and Self Control of Health Between AIDS Infected and Non-infected Person in Bamras Naradool Institute. Thesis of Master of Science (Developmental Psychology). Bangkok: Ramkhamhaeng University.

Shek, D.T.L. (1995). Marital Quality and Psychological Well-being of Married Adults in a Chinese Context. Journal of Genetic Psychology, 156(1), 45-46. 
Social Development and Human Security Ministry. (2004). Social Situation Report. Social Situation, Family Situation for 2004, (January-March), 1(2), 3-18.

Sucaromana, A., \& Choochom, O. (2005). Program for Enhancing Emotional Intelligence Based on Oriental Approach for the Better Quality of Life in Thai Youths. Journal of Behavioral Science, 11(1), 19-32.

Tangcholthip, R. (1987). The Effect of Buddhist Meditation Practice on School Children's Mental Health. Thesis of Master of Education (Clinical Psychology). Bangkok: Mahidol University.

Trakoolsalit, W. (2002). Adaptation Psychology. Bangkok: Academic Promotion Center.

Vanindananda, N. (2009). Family, Religion, School and Socialization on Buddhist Religious of Thai Youths: A Research Review in Behavioral Science. Journal of Social Development, 11(1), 25-60.

Wattanasiritham, P. (2006). Articles from Bangkok Business Website. [Online] Available: http://gotoknow.org/blog/paiboon/58087. (December 1, 2006)

Table 1. Randomized Control Group Pretest Posttest design

\begin{tabular}{c|c|c|c|c}
\hline Group & Pretest(T1) & Treatment & $\begin{array}{c}\text { Posttest } \\
\text { (T2) }\end{array}$ & After 3 months Test \\
\hline Experimental & $\mathrm{T} 1, \mathrm{Ts}, \mathrm{Tn}, \mathrm{Tc}$ & $\mathrm{X}$ & $\mathrm{T} 2$ & $\mathrm{Tw}$ \\
\hline Control & $\mathrm{T} 1 \mathrm{Ts}, \mathrm{Tn}, \mathrm{Tc}$ & - & $\mathrm{T} 2$ & $\mathrm{Tw}$ \\
\hline
\end{tabular}

Notes:

$\mathrm{T} 1, \mathrm{~T} 2=$ Perception of life crisis measurement

Ts $\quad=$ Social support measurement

Tn $\quad=$ Neuroticism measurement

$\mathrm{Tc}=$ Self control measurement

Tw $\quad=$ Well-being measurement

Table 2. Cronbach Coefficients of the Questionnaires

\begin{tabular}{l|c|c}
\hline Questionnaire & No. of items & Reliability Coefficient \\
\hline 1. Perception of life crisis & & \\
$\quad$ - Stress & 16 & .8883 \\
- Emotion oriented coping & 10 & .8171 \\
- Adaptation & 14 & .9128 \\
2. Neuroticism & 11 & .8623 \\
3. Self control & 10 & .6318 \\
4. Social support & 13 & .8985 \\
5. Well-being & 13 & .8760 \\
\hline
\end{tabular}

Table 3. Comparison between the scores of the perception of life crisis of women who had been trained by MLCP and those not trained

\begin{tabular}{l|c|c|c}
\hline Effect & $\begin{array}{c}\text { Wilks' } \\
\text { Lambda }(\lambda)\end{array}$ & $\begin{array}{c}\text { Multivariate } \\
\text { F-test }\end{array}$ & Sig \\
\hline Before training & 0.94 & 1.61 & 0.19 \\
$\begin{array}{l}\text { Between experimental group and control } \\
\text { group }\end{array}$ & & & \\
$\begin{array}{l}\text { After training } \\
\begin{array}{l}\text { Between experimental group and control } \\
\text { group }\end{array}\end{array}$ & 0.80 & 5.52 & $0.00^{*}$ \\
\hline
\end{tabular}

Note: $* \mathrm{p}<0.05$ 
Table 4. Variance of each term of Life Crisis score (stress, emotion oriented coping and adaptation) comparing women who had been trained with MLCP and those who had not been trained

\begin{tabular}{l|c|c|c|c|c}
\hline Source of variance & Sum of Square & $d f$ & Mean Square & $\begin{array}{c}\text { Univariate } \\
\text { F-test }\end{array}$ & Sig \\
\hline After training & & & & & \\
Between experimental group & & & & & \\
and control group & & & & & \\
- stress & 79.34 & 1 & 79.34 & 0.64 & 0.43 \\
- emotion oriented coping & 125.43 & 1 & 125.43 & 6.69 & $0.01^{*}$ \\
- adaptation & 516.00 & 1 & 516.00 & 16.13 & $0.00^{*}$ \\
\hline
\end{tabular}

Notes: $\quad \mathrm{R}^{2} \quad=0.187$ (Adjusted $\left.\mathrm{R}^{2}=0.176\right),{ }^{*} \mathrm{p}<0.05$

Table 5. Multiple analysis of variances (MANOVA) of overall life crisis perception of women in the experimental group and control group

\begin{tabular}{l|c|c|c}
\hline $\begin{array}{l}\text { Source of variance } \\
\text { Within experimental group }\end{array}$ & $\begin{array}{c}\text { Wilks' } \\
\text { Lambda }(\lambda)\end{array}$ & $\begin{array}{c}\text { Multivariate } \\
\text { F-test }\end{array}$ & Sig \\
\hline $\begin{array}{l}\text { Before - After MLCP training } \\
\text { Within control group }\end{array}$ & 0.575 & 7.148 & $0.00^{*}$ \\
\hline Before-After being suggested self massage & 0.878 & 1.711 & 0.18 \\
\hline
\end{tabular}

Note: $* \mathrm{p}<0.05, * * \mathrm{p}<0.01$

Table 6. Multiple analysis of variances (MANOVA) for each variable of the life crisis score (stress, emotion oriented coping and adaptation) of women within experimental group and control group

\begin{tabular}{l|c|c|c|c|c}
\hline Source of variance & $\begin{array}{c}\text { Sum of } \\
\text { Square }\end{array}$ & $\boldsymbol{d f}$ & $\begin{array}{c}\text { Mean } \\
\text { Square }\end{array}$ & $\begin{array}{c}\text { Univariate } \\
\text { F-test }\end{array}$ & Sig \\
\hline Within experimental group & & & & & \\
Before-After training & 159.39 & 1 & 159.39 & 1.99 & 0.17 \\
- stress & 462.25 & 1 & 462.25 & 16.11 & $0.00^{*}$ \\
- emotion oriented coping & 415.14 & 1 & 415.14 & 8.29 & $0.01^{*}$ \\
- adaptation_ & & & & & \\
Within control group & & & & & \\
Before-After training & 66.61 & 1 & 66.61 & 0.81 & 0.37 \\
- stress & 86.11 & 1 & 86.11 & 3.23 & 0.08 \\
- emotion oriented coping & 64.80 & 1 & 64.80 & 2.34 & 0.13 \\
- adaptation
\end{tabular}

Note: $* \mathrm{p}<0.05$ 


\section{Independent Variables}

\section{Experimental Group}

1. Relaxation by exercise with light music.

2. Emotional control by meditation.

3. Emotion oriented coping by listening to $\mathrm{CD}$ of Taoism doctrine.

4. Adaptation by recreation of group activity.

5. Adaptation to the society by joining a social benefit activity.

6. Self - Thai traditional massage.

\section{Control group}

1. Did not train in MLCP

2. Were advised to train in self massage.

3. Were given documents related to MLCP

Social support from spouse or children

1. Were given positive communication to promote will- power and strengthen force.

2. Were given feedback about behavior.

3. Were given assistance to reduce burden in family.

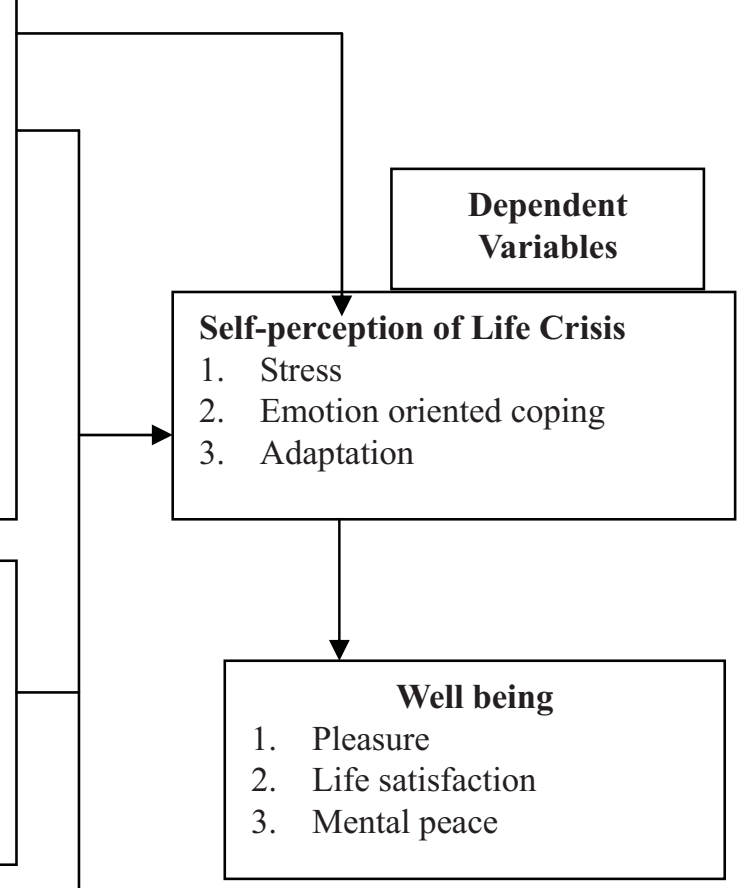

Psychological factors of Thai married women

1. Neuroticism.

2. Self control

Figure 1. Theoretical Framework Guiding Research 